\title{
Role of Micro and Nano Filler Combination in Hydrophobic Recovery of Glass Fiber Reinforced Epoxy Composites under Various Contaminants
}

\author{
Santhy P. Kuruvilla, N. M. Renukappa
}

\begin{abstract}
Use as outdoor insulators in high voltage power transmission is a potential application of epoxy composites. Vulnerability of these insulators to various stresses when exposed to external environment, limit their potential. Better pollution performance in hostile environments can be achieved in these composites by using nano and micro combination of fillers. This paper discusses the merits of using combination of micro and nano fillers consisting of silica, alumina, $\mathrm{ATH}, \mathrm{CaCO}_{3}$ and $\mathrm{MgO}$ in glass epoxy to demonstrate that they serve a better alternative to the conventional glass epoxy composite insulation systems. Extensive investigations have been carried out on hydrophobic recovery of these composites for understanding their pollution performance under various contaminants such as $\mathrm{NaCl}$, seawater, acid and cement. The addition of filler combinations to glass epoxy enhanced the hydrophobic properties of the composites compared to the glass epoxy without fillers. The results revealed that the composite with $\mathrm{MgO}$ filler showed $37 \%$ increase in contact angle in as-cast form compared to contact angle of epoxy without fillers.
\end{abstract}

Keywords: Contact angle, hydrophobic recovery, glass epoxy composites, pollution performance.

\section{INTRODUCTION}

Extensive research investigations have been carried out on surface wetting phenomena in outdoor polymers for understanding the performance of composites under contaminated conditions $[1,2,4-7]$. The wettability in general describes the capability of the liquids to spread on the polymer surface. It is also recognized that a proper assessment of surface wetting characteristics of the material can be established by measurement of contact angle of liquids on the surface of solids [3]. This paper discusses the effect of different contaminants on the contact angle of silicone and glass reinforced epoxy composites. Using a combination of fillers consisting of silica, alumina, ATH, Magnesium oxide and calcium carbonate, three different epoxy composites namely GESAA, GESAC and GESAM were developed and their surface wetting characteristics/ hydrophobicity has been analyzed. The contact angle was measured by subjecting these materials to five different contaminants having different electrical conductivity and

Revised Manuscript Received on February 25, 2020.

* Correspondence Author

Santhy P. Kuruvilla, JSS Research foundation, JSSTI Campus, Mysuru, Karnataka, India Email: shantyajish_ece@mitmysore.in

N. M. Renukappa*, Department of Electronics \& Communication Engineering, JSS Science and Technology University, Mysuru, Karnataka, India. Email: renunijagal@gmail.com

(C) The Authors. Published by Blue Eyes Intelligence Engineering and Sciences Publication (BEIESP). This is an open access article under the CC BY-NC-ND license (http://creativecommons.org/licenses/by-nc-nd/4.0/) salinity. An attempt is made to evaluate the relative recovery characteristics when subjected to ambient conditions for $2000 \mathrm{~h}$ after immersing them in five different contaminants.

\section{MATERIALS AND METHODS}

\section{A. Materials}

The details of the source of the materials, the weight percentage of epoxy, filler and glass fiber reinforcement used in the fabrication of the composites are shown in Table I and II respectively.

\section{B. Fabrication}

Epoxy composites were fabricated using epoxy resin with surface functionalized long ECR-glass fiber. The coupling agent used was 3-glycidyloxypropyl trimethoxy silane. Since nano silica and nano alumina are established to impart improvement in dielectric properties, while micrometer sized $\mathrm{ATH}, \mathrm{CaCO}_{3}$ and $\mathrm{MgO}$ are known to impart distinct advantages to the composites, combination of these fillers has been used and the reasons for selection of fillers is outlined in an earlier publication [8]. To reduce the viscosity and to eliminate the moister content, epoxy resin and hardener were pre-treated in a vacuum chamber for $1 \mathrm{~h} 15$ min at $65{ }^{\circ} \mathrm{C}$ before mixing. Similarly, before mixing, $\mathrm{SiO}_{2}$, $\mathrm{Al}_{2} \mathrm{O}_{3}, \mathrm{ATH}, \mathrm{CaCO}_{3}$ and $\mathrm{MgO}$ filler particles were preheated in an oven for $24 \mathrm{~h}$ at $115^{\circ} \mathrm{C}$. The fillers were dispersed through gentle stirring in absolute ethanol. To disperse the nano/micro particles uniformly in the epoxy resin, Ultrasonication and high-speed shearing were employed. Silane coupling agent was mixed and hydrolyzation occurred after $15 \mathrm{~min}$. Then epoxy resin was mixed with the composite, followed by sonication for 45 min. The accelerator, release agent and the hardener were mixed using a high shear mixer at $3500 \mathrm{rpm}$. Before pultrusion, glass fibers were modified with silane coupling agent for improving the interfacial adhesion between the resin and glass fibers. The weight was maintained at $78 \mathrm{wt}$. $\%$ in all the composites during reinforcement of ECR-glass fiber.

Using a table-top lab-scale pultrusion machine, the composite rods were fabricated. The machine consisted of a resin bath, pultrusion die and a puller. Skeins with the required amount of fibers for the given wt. \% of the primary reinforcement were made by winding the glass fiber roving on a former. After soaking in resin, the skeins were pulled into flared glass tubes by allowing the resin to settle prior to post-curing at a temperature of $80^{\circ} \mathrm{C}$ for $4 \mathrm{~h}$. 
Table- I: Details of materials used in fabrication of Composites

\begin{tabular}{|c|c|c|c|}
\hline No & Materials & Source & Density $\left(\mathrm{g} / \mathrm{cm}^{3}\right)$ \\
\hline 1 & Epoxy & Huntsman, USA & 1.16 \\
\hline 2 & $\begin{array}{l}\text { ECR glass } \\
\text { fiber }\end{array}$ & $\begin{array}{l}\text { Owens Corning, } \\
\text { India }\end{array}$ & 2.62 \\
\hline 3 & $\begin{array}{l}\text { Alumina } \\
\text { (Nano) }\end{array}$ & \multirow{4}{*}{$\begin{array}{l}\text { Sigma Aldrich, } \\
\text { USA }\end{array}$} & 4.0 \\
\hline 4 & $\begin{array}{l}\text { Silica } \\
\text { (Nano) }\end{array}$ & & 2.6 \\
\hline 5 & $\begin{array}{l}\mathrm{CaCO}_{3} \\
\text { (Micro) }\end{array}$ & & 2.9 \\
\hline 6 & $\begin{array}{l}\text { MgO } \\
\text { (Micro) }\end{array}$ & & 3.6 \\
\hline 7 & $\begin{array}{l}\text { ATH } \\
\text { (Micro) }\end{array}$ & Akrochem Corp. & 2.4 \\
\hline 8 & Silicone & $\begin{array}{l}\text { Navitas Insulators, } \\
\text { India }\end{array}$ & 2.1 \\
\hline
\end{tabular}

Table- II: Details of epoxy, glass fiber and filler percentages used (weight percentages used are indicated by the numbers in parenthesis)

\begin{tabular}{|l|l|}
\hline Sample & Details \\
\hline GE & ECR glass fiber reinforced (78) epoxy (22) \\
\hline GESAA & $\begin{array}{l}\text { ECR glass fiber (75) reinforced epoxy (15) } \\
\text { with nano-silica (2) + nano alumina (3) } \\
+ \text { micro ATH (5) }\end{array}$ \\
\hline GESAC & $\begin{array}{l}\text { ECR glass fiber (75) +epoxy (15) + nano } \\
\text { silica (2) + nano alumina (3) + micro CaCO } 3 \\
(5)\end{array}$ \\
\hline GESAM & $\begin{array}{l}\text { ECR glass fiber (75) + epoxy (15) + nano } \\
\text { silica (2) + nano alumina (3) + micro MgO } \\
(5)\end{array}$ \\
\hline
\end{tabular}

\section{Selection of Contaminants}

The contaminants used in this investigation are listed in Table III along with their electrical conductivity, salinity and $\mathrm{pH}$ values. In this study, $\mathrm{NaCl}$ solution, cement solution, sea water, tap water and $\mathrm{H}_{2} \mathrm{SO}_{4}$ were also used as contaminants [9-15], keeping in mind wide range of applications of the fiber reinforced composites. Sea water is different in its constituents from $\mathrm{NaCl}$ since it has ions of $\mathrm{Na}, \mathrm{Mg}$. Ca, K. Br, Fl, sulphates, $\mathrm{HCO}_{3}$ and Bromine. Sea water is alkaline and $\mathrm{Ca}++$ and $\mathrm{HCO}_{3}{ }^{-}$forms insoluble $\mathrm{CaCO}_{3}$. $\mathrm{Al}$ and Iron Oxide coagulate to form colloidal solutions [16]. The constituents of tap water [17] are different from that of sea water in that it has $\mathrm{Cl}, \mathrm{Fl}$, trihalomethanes, in addition to $\mathrm{As}, \mathrm{Pb}, \mathrm{Hg}, \mathrm{Al}, \mathrm{Ba}, \mathrm{Cd}$, some sulphates, pesticides, organic matter, microbiological contents like algae and bacteria. It has a $\mathrm{pH}$ of 8 and compounds like $\mathrm{SO}_{2}$ and $\mathrm{NOx}$ dissolve easily in water and are carried by wind to form acid fog with $\mathrm{pH}$ of 4.2 to 4.4. Hence the effect of acid was also studied. The composites were immersed in the contaminants for $1000 \mathrm{~h}$ and measurement of the contact angle was carried out at regular intervals.

The details of the contaminants selected with their electrical conductivity, salinity and $\mathrm{pH}$ values are shown in Table III.
Table- III: Details of the contaminants used

\begin{tabular}{|l|l|l|l|l|}
\hline No. & Contaminant & $\begin{array}{l}\text { Conductivity (mS) } \\
\left(\mathbf{a t ~ 2 5}^{\mathbf{}} \mathbf{C} \text { and } \mathbf{5 5} \%\right. \\
\mathbf{R H})\end{array}$ & $\mathbf{p H}$ & $\begin{array}{l}\text { Salinity } \\
\mathbf{k g} / \mathbf{m}^{\mathbf{3}}\end{array}$ \\
\hline 1 & $\mathrm{NaCl}$ & 15 & 8.44 & 8.875 \\
\hline 2 & Cement & 15 & 11 & 8.875 \\
\hline 3 & Sea Water & 46 & 7.56 & 30.03 \\
\hline 4 & Tap Water & 1.2 & 7.94 & 0.57 \\
\hline 5 & Acid & 0.95 & 4.0 & 0.44 \\
\hline
\end{tabular}

For the measurement of the contact angle, Hollmarc instrument was used. The samples were initially conditioned at a temperature of $25 \pm 2{ }^{\circ} \mathbf{C}$ and $55 \pm 5 \%$ RH before commencement of the measurements. Stability of the applied drop on the specimen was ensured by orienting the samples were horizontally oriented so that the applied drop was stable on the specimen. Using a hypodermic syringe, a $2 \mu \mathrm{L}$ drop of the liquid was placed on the horizontal surface of the sample. A high-resolution digital camera was used to take photographs of drops. The recorded data of the contour of the drop was then analyzed using "ImageJ" software [18]. For measurements, samples measuring $5 \mathrm{~cm} \mathrm{x} 10 \mathrm{~cm}$ were used. During the long duration immersion experiments, the specimens were removed periodically and were wiped with a clean dry cloth and immediately subjected to measurements. The measurements were completed within 5 min after removal from the container with the contaminants. In this investigation the surface wetting angle of polymer has been evaluated as a function of duration of exposure to the contaminants. To assess the capability of composites to recover the hydrophobicity which in turn is related to the wetting angle, the polymers were conditioned at ambient temperatures of $25 \pm 5{ }^{\circ} \mathrm{C}$ and $\mathrm{RH}$ of $55 \pm 5 \%$ for a further period of $2000 \mathrm{~h}$ and contact angle measurements were carried out.

\section{RESULTS AND DISCUSSION}

\section{A. Assessment of Influence of Contaminants on CA Of Composites}

The initial surface contact angle (CA) of the composites (virgin) is furnished in Table IV. The results revealed that the composite with MgO filler showed 37\% increase in CA as compared to CA of glass-epoxy without fillers. The method of fabrication of composites and uniform distribution of the two nano fillers and the micro filler is critical for improving the CA and also for its recovery. Use of saline coupling agent improves the interfacial bonding between nano alumina, silica particles and the incorporation of micro sized fillers namely $\mathrm{ATH}, \mathrm{CaCO}_{3}$ and $\mathrm{MgO}$ further enhances the interfacial strength. Depending upon the relative sizes, shape and placement of the filler in the epoxy matrix, the pathway for water diffusion will be different. The distribution of the nano and micro fillers within the epoxy matrix will ultimately decide the pathway for transport of contaminants. 
It is also essential to understand that the free volume in these epoxies will be different because of the differences in the filler particle

size of ATH $(2.6 \mu \mathrm{m}), \mathrm{CaCO}_{3}(5 \mu \mathrm{m})$ and $\mathrm{MgO}(8 \mu \mathrm{m})$ and their distribution in the matrix.

Table- IV: Initial CA with Standard Deviation in percentage

\begin{tabular}{|l|c|c|}
\hline Composites & $\begin{array}{c}\text { CA (as-cast) } \\
\left({ }^{\circ}\right)\end{array}$ & $\begin{array}{c}\text { Standard } \\
\text { Deviation (\%) }\end{array}$ \\
\hline GE & 86 & 1.95 \\
\hline GESAA & 100 & 1.86 \\
\hline GESAC & 110 & 1.83 \\
\hline GESAM & 118 & 1.76 \\
\hline Silicone & 114 & 1.65 \\
\hline
\end{tabular}

The free space length [18] in the material microstructure is computed to be maximum in GE $(1800 \mu \mathrm{m})$ and it is very much reduced $(60-80 \mu \mathrm{m})$ in filled GE. Analysis of free volume GE composites using Positron Annihiliation spectrocopy have revealed that the GE has higher free volume (of about $60 \AA 3$ ) as compared to GESAA, GESAC an GESAM (of $50 \AA 3$ ) leading to higher water absorption in GE. Thus nano- $\mathrm{Al}_{2} \mathrm{O}_{3}$, nano- $\mathrm{SiO}_{2}$ and micro-ATH, $\mathrm{CaCO}_{3}$ and $\mathrm{MgO}$ fillers improve the cross linking and thus help in reducing the chain mobility. Further, from the data of Positron spectroscopy, the fillers due to their relative

dimensions appear to be located in between the chain segments and not in free volume cavities. Thus, the water molecules occupy the free volume in the epoxy materials and the results agree with the reported studies [1-2].

The data of CA variations with $\mathrm{NaCl}$, cement solution, sea water, tap water and acid are shown in Table V. Except silicone all the GE materials studied lose their hydrophobicity due to long-duration exposure to contamination. However, with increase in duration of exposure GESAA and GESAM tend to recover partially their hydrophobicity.

In fact, GESAM regains its hydrophobicity to a better extent than the other two GE materials with fillers. Therefore, the performance of the five materials on a comparative scale show that silicone is least affected by $\mathrm{NaCl}$. On the other hand, GESAM exhibits a better performance followed by GESAA, GESAC and GE when exposed to $\mathrm{NaCl}$. The data of $\mathrm{CA}$ variations with $\mathrm{NaCl}$, cement solution, sea water, tap water and acid is shown in Table V. It is observed that throughout the $1000 \mathrm{~h}$ period of immersion in cement, silicone is able to retain its contact angle. The results also show that GESAC and GESAM retain their hydrophobicity during the $1000 \mathrm{~h}$ period. Thus, the CA of silicone, GESAC and GESAM has shown that their surfaces are not influenced by cement.

From results of $1000 \mathrm{~h}$ immersion in seawater, silicone and GESAC appear to perform relatively better as compared to GE and GESAA and GESAM. However, all the GE composites lose their hydrophobicity when exposed to tap water for 1000 h. Further, with acid, Silicone and GESAM retains hydrophobicity at the end of $1000 \mathrm{~h}$. Thus, the variation in contact angle depends upon the contaminant type, particle size and free volume in the bulk of the GE composite.

Table- V: The data of CA variations with $\mathrm{NaCl}$, cement solution, sea water, tap water and acid

\begin{tabular}{|c|c|c|c|}
\hline Contaminant & Composite & $\begin{array}{l}\text { CA of } \\
\text { virgin } \\
\text { surface }\end{array}$ & $\begin{array}{c}\text { Average } \\
\text { CA } \\
\text { During 50- } \\
\text { 1000h } \\
\text { of } \\
\text { exposure }\end{array}$ \\
\hline \multirow[t]{5}{*}{$\mathrm{NaCl}$} & Silicone & 114 & 109 \\
\hline & $\mathrm{GE}$ & 86 & 71 \\
\hline & GESAA & 100 & 89 \\
\hline & GESAC & 110 & 85 \\
\hline & GESAM & 118 & 92 \\
\hline \multirow[t]{5}{*}{ Cement } & Silicone & 114 & 114 \\
\hline & GE & 86 & 65 \\
\hline & GESAA & 100 & 85 \\
\hline & GESAC & 110 & 101 \\
\hline & GESAM & 118 & 92 \\
\hline \multirow[t]{5}{*}{ Seawater } & Silicone & 114 & 105 \\
\hline & GE & 86 & 63 \\
\hline & GESAA & 100 & 80 \\
\hline & GESAC & 110 & 90 \\
\hline & GESAM & 118 & 83 \\
\hline \multirow[t]{5}{*}{ Tap water } & Silicone & 114 & 108 \\
\hline & $\mathrm{GE}$ & 86 & 56 \\
\hline & GESAA & 100 & 64 \\
\hline & GESAC & 110 & 54 \\
\hline & GESAM & 118 & 57 \\
\hline \multirow[t]{5}{*}{ Acid } & Silicone & 114 & 106 \\
\hline & GE & 86 & 60 \\
\hline & GESAA & 100 & 82 \\
\hline & GESAC & 110 & 82 \\
\hline & GESAM & 118 & 92 \\
\hline
\end{tabular}

\section{B. Assessment of Recovery of Contact Angle After The Exposure to Contaminants}

The ability of materials to recover hydrophobicity after their exposure to contaminants for $1000 \mathrm{~h}$ was investigated and the results are discussed in this section. All the materials were exposed to ambient conditions at $25 \pm 5^{\circ} \mathrm{C}$ and a $\mathrm{RH}$ of $55 \pm 5 \%$ for $2000 \mathrm{~h}$ and variations in the CA were recorded.

\section{a. Recovery of contact angle of silicone}

The data of CA during $2000 \mathrm{~h}$ of exposure to ambient conditions after $1000 \mathrm{~h}$ conditioning with $\mathrm{NaCl}$, sea water, cement, tap water and acid in case of silicone is shown in Fig.1. It is observed that silicone recovers its hydrophobicity completely since contact angle reaches a value of 114 with $\mathrm{NaCl}$. Thus, silicone has a remarkable ability to retain and maintain a relatively higher contact angle. It is observed that in case of other four contaminants, namely cement, sea water, tap water and acid there is a recovery from $112 \pm 2^{\circ}$ to $113 \pm 1^{\circ}$ during exposure to ambient conditions for 250 to $1000 \mathrm{~h}$ and the CA settles down to $113 \pm 1^{\circ}$ irrespective of the contaminants used. 
Thus, silicone exhibits unique characteristics in that the reduction in contact angle is from $114^{\circ}$ (virgin) to $107^{\circ}$ (lowest in case of seawater). However, the data of contact angle as a function of time duration under ambient conditions has demonstrated that silicone has the capability to recover during the off periods of contamination. The recovery of CA also demonstrates that the pollutants do not penetrate deeper in to the bulk and are easily removed because of their presence at the top surface.

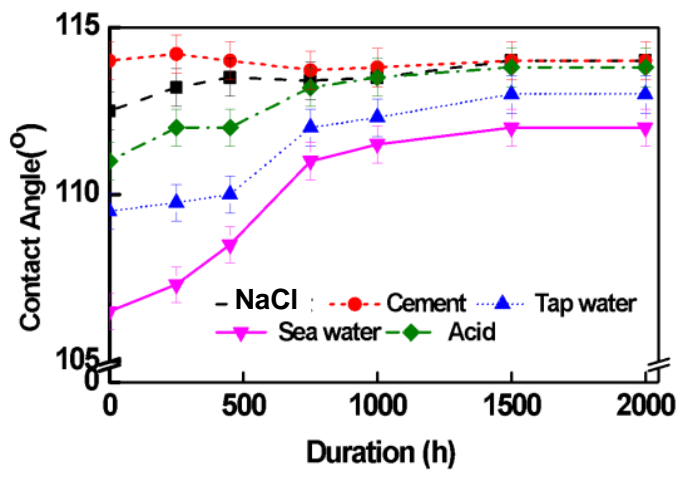

Fig. 1. Variation of contact angle of Silicone with duration of exposure to ambient conditions after $1000 \mathrm{~h}$ conditioning

\section{b. Recovery of Contact Angle of GE}

The variations of CA during $2000 \mathrm{~h}$ of exposure to ambient conditions after 1000 h conditioning with $\mathrm{NaCl}$, sea water, cement, tap water and acid in case of GE is shown in Fig.2.

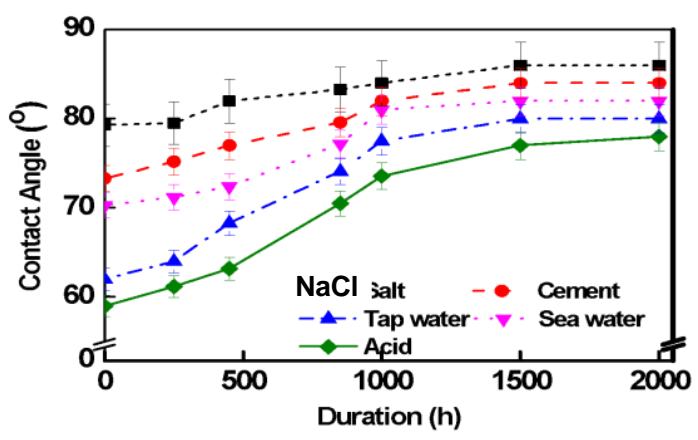

Fig. 2. Variation in CA for GE with duration of exposure to ambient conditions after $1000 \mathrm{~h}$ exposure to $\mathrm{NaCl}$, cement, tap water, sea water and acid

The base material remains hydrophilic even after $2000 \mathrm{~h}$ of exposure to ambient conditions though it shows marginal recovery from 58 to 78 in case of acid contamination and to a maximum of 80 to $86^{\circ}$ in case of sample with cement contamination. Thus, influence of cement on CA of base material is marginal and is closer to the lower end of hydrophobicity. After contamination of $1000 \mathrm{~h}$ it is observed that the recovery is better in the first $800 \mathrm{~h}$ and there after only a marginal improvement beyond $800 \mathrm{~h}$ is observed. Ultimately, it is observed that the contact angle values converge towards an average value of 73 to $83^{\circ}$.

\section{c. Recovery of CA of GESAA}

The results of variation of CA of GESAA during $2000 \mathrm{~h}$ of exposure to ambient conditions after $1000 \mathrm{~h}$ conditioning with $\mathrm{NaCl}$, sea water, cement, tap water and acid are shown in Fig.3. Interestingly after $2000 \mathrm{~h}$ of conditions under ambient conditions GESAA regains its hydrophobic nature though the values are marginally lower (by 10\%) than the virgin material. At the end of $2000 \mathrm{~h}$ of exposure to ambient condition GESAA is able to reach a CA level of 93 with cement, tap water and salt contaminants which is closer to the lower end of hydrophobicity. However, in the case of sea water and acid, the CA falls slightly below $90^{\circ}$. In this case, beyond $1500 \mathrm{~h}$ of exposure, the contact angle converges to an average value of $85^{\circ}$. Thus, exposure of GESAA to ambient conditions helps in recovery of contact angle to a level lower than the range of hydrophobicity range.

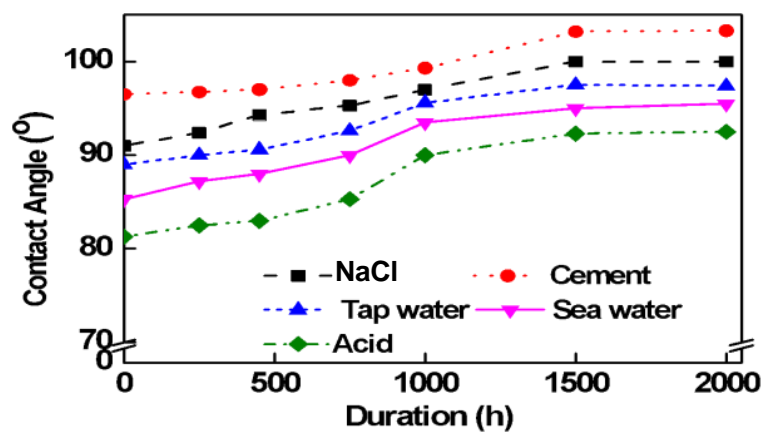

Fig. 3. Variation in CA for GESAA with duration of exposure to ambient conditions after $1000 \mathrm{~h}$ exposure to $\mathrm{NaCl}$, cement, tap $\mathrm{p}$ water, sea water and acid.

\section{d. Recovery of CA of GESAC}

The data of recovery of CA of GESAC is shown in Fig. 4. In GESAC, significant recovery of CA is observed during the first $500 \mathrm{~h}$ of exposure and the composite regains the hydrophobic nature. During 250 h of exposure to ambient conditions significant recovery of CA is seen in case of $\mathrm{NaCl}$, tap water, and acid. However, in the case of cement, the average value of CA is around 107 with a variation of \pm 3 during the $1000 \mathrm{~h}$ period. After $2000 \mathrm{~h}$ of conditions under ambient conditions, the recorded values of CA average to $105^{\circ}$.

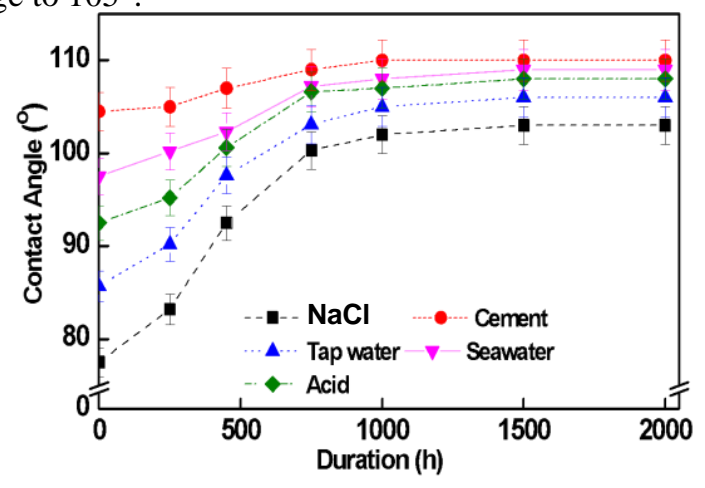

Fig. 4. Variation in CA for GESAC with duration of exposure to ambient conditions after $1000 \mathrm{~h}$ exposure to $\mathrm{NaCl}$, cement, tap water, sea water and acid. 


\section{e. Recovery of CA of GESAM}

The variation in CA for GESAM with duration of exposure to ambient conditions for $2000 \mathrm{~h}$ after immersion in $\mathrm{NaCl}$, cement, tap water, sea water and acid is shown in Fig 5. There is consistent recovery of CA during first $1000 \mathrm{~h}$ of exposure and beyond this point; the rate of recovery of CA is reduced. After $1000 \mathrm{~h}$ of exposure to ambient condition, the CA is observed to settle around $110^{\circ}$ in case of $\mathrm{NaCl}$, cement and acid. This is in contrary to previous cases, in which recovery was observed only during the first $250 \mathrm{~h}$ of exposure. GESAC is observed to regain its hydrophobicity in a better manner up to $800 \mathrm{~h}$ and the average value of CA of GESAM material is $108^{\circ}$.

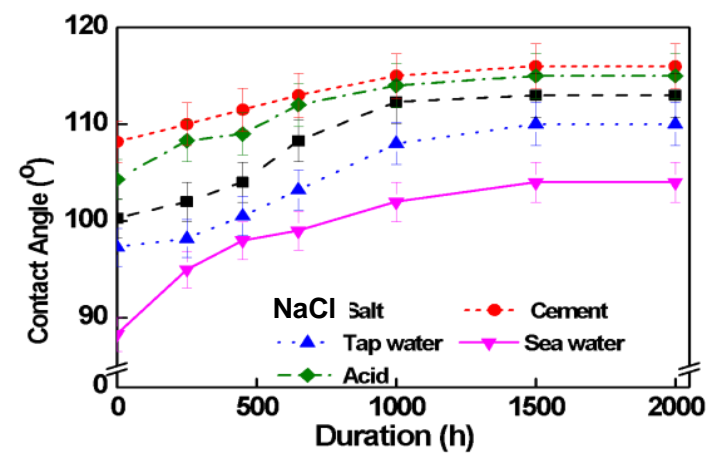

Fig. 5. Variation in CA for GESAM with duration of exposure to ambient conditions after $1000 \mathrm{~h}$ exposure to $\mathrm{NaCl}$, cement, tap water, sea water and acid

Silicone has remarkable ability to recover hydrophobicity under ambient conditions. It recovers hydrophobicity completely in case of $\mathrm{NaCl}$ at higher salinities. GESAA exhibits good ability to recover hydrophobicity with cement, $\mathrm{NaCl}$, tap water, sea water and acid. GESAC shows improvement over GESAA in its ability to recover hydrophobicity irrespective of the contaminants. GESAM also shows comparatively better ability to recover hydrophobicity as compared to GESAC. However, after $1000 \mathrm{~h}$ of exposure to ambient conditions, there is total recovery of hydrophobicity. There is a considerable reduction in hydrophobicity with $\mathrm{NaCl}$, in all GE based material.

\section{Water Diffusion Dynamics}

Water diffusion dynamics in reinforced epoxy is determined by three different mechanisms [16], namely (i) diffusion through the micro gaps of the polymer chains, (ii) capillary transport through the gaps present at the interfaces of the fillers and the matrix and (iii) the transport through the micro-cracks, if present. Diffusion is broadly classified into Fickian, non-Fickian or anomalous diffusion, and a case in between the Fickian and non- Fickian. Some authors have used the Langmuir diffusion model to explain diffusion of water into silicone [19] and which is classified under anomalous diffusion which accounts in a better way for the presence of bound water molecules.

Fickian diffusion is characterized by a slow rate of diffusion of the liquid. This is due to mechanical, structural and similar modes of penetrant-polymer system interactions. Non-Fickian type of diffusion occurs faster than the segmental relaxation processes. The long-duration drift in absorption kinetics of polymers is attributed to the mass uptake of water, which is controlled by the visco-elastic relaxation of the polymer chains which help to accommodate the penetrant [20].

It is observed from water absorption measurements that GE, GESAA, GESAC and GESAM follow the Fickian diffusion to the extent of $70,72,77$ and $90 \%$ and it goes further higher in silicone. Epoxy absorbs water more than the glass fibers at a slightly higher rate, and the absorbed water molecules bond either with the amine or hydroxyl groups. The unbonded or the free water molecules cluster around the free volume inside the epoxy [2]. The reduction in CA during the initial period of immersion $(<200 \mathrm{~h})$ in contaminants demonstrates the time dependence and the role of micro structure in the diffusion mechanisms. The recovery of CA is also observed to depend on the nature of the contaminant and the microstructure which in turn dependence on the size, shape and placement of the fillers in the epoxy matrix. Incorporation of two nano and one micro filler leads to micro structural changes and the pathway for transport of water inside the bulk is made difficult as a consequence of the tortuous pathway.

\section{CONCLUSION}

Some of the important conclusions drawn from the investigations are:

1. Silicone retains its hydrophobicity with different contaminants.

2. The time dependence of CA variations on immersion in contaminants is attributed to the involvement of different diffusion mechanisms.

3. In case of the epoxy composites, the fillers help to enhance the contact angle and impart different surface wetting properties under contaminations.

4. The use of nano and micro filler combination in the GE matrix leads to considerable improvement in the initial CA and retention of hydrophobicity.

5. Calcium carbonate and Magnesium oxide filers hold promise when combined with alumina and silica.

\section{REFERENCES}

1. Zhao, Zhu, Mei, Wang and Guan, Influence of environmental factors on hydrophobicity transfer property of silicone rubber material, Electr. Insul. Conf., Washington, USA, 7-10, 2015.

2. N. Marvikakis, K. Siderakis, E. Koudomus, E.Drakakis, E.Kimakis, Laboratory investigation of the hydrophobicity transfer mechanism on material insulators aged in costal service, Eng. Technol. Appl. Sci. Res., vol. 6, 2016, no. 5, 1145-1129.

3. T. Tokoro and R. Hackam, Loss and recovery of hydrophobicity and surface energy of HTV silicone rubber, IEEE Trans. Dielectr. Electr. Insul., vol. 8, 2001, no.6, pp. 1088 - 1097.

4. T.Tanaka, Aging of material and polymeric insulating materialsAspects of interfacial performance in aging, IEEE Trans. Dielectr. Electr. Insul., vol. 9, 2002, no.5. pp. 704-716.

5. M.Mackiewicz, J.I. Mikulski, J. Wankowicz, S. Kucharski, P.Ranachowski,Z. Ranachowiski, Study of material insulator sheds subjected to wheel test, Arch. Metall. Mater, vol. 62, 2017, pp. 679686.

6. N.Hameed, S.P.Thomas, R.Abraham, S.Thomas, Morphology and contact angle studies of poly (styrene-co-acrylonitrile) modified epoxy resin blends and their glass fiber rein forced composites, eXPRESS Polym Lett., vol. 1, 2007, no. 6, pp. 345-355.

7. Evaluation of dynamic hydrophobicity properties of polymeric materials for non-ceramic out door insulation-Retention and transfer of hydrophobicity, CIGRE working group, D1.14, December 2010. 
8. Santhy P.Kuruvilla, N.M.Renukappa, J.Sundara Rajan, Development of Epoxy with micro and nano fillers for core insulation of composite insulators, IEEE Inter. Conf. on high vlg. Engg. 2019,

9. $\quad$ S.C.Mohanty, B.P.Singh, K.K.Mahato, D.K. Rathore,R.K.Prushty, B.C.Ray, Water absorption behaviour and residual strength assessment of glass/epoxy and carbon/epoxy hybrid material, 5th National Conference on Processing and Characterisation of Materials, IOP Conf. Series Material science and Engg 115, 2016.

10. J.Yao and G. Ziegmann, Water absorption behaviour and its influence on properties of GRP pipe, Journal of material Materials, vol. 41, 2007, no.8, pp. 993-1008.

11. J.Kim, M.K.Choudhary and M.J.Owen, Hydrophobicity loss and recovery of silicone H.V. insulation, IEEE Trans. Dielectr. Electr. Insul., vol. 6, 1999, no.5, 695-702.

12. Martin Reading, Zhiqiang $\mathrm{Xu}$, Alun S. Vaughan and Paul L. Lewin, The thermal and electrical properties of nano-silicon dioxide filled epoxy systems for use in high voltage insulation, Electrical Insulation Conference, Annapolis, Maryland. 2011

13. H. Couderc, I. Preda, M. Frechette, S. Savoie, M. Reading, A.S Vaughan, J. Castellon, Dielectric Properties of Boron Nitride and Silica Epoxy Composites, IEEE Xplore.2012

14. Muhammad Amin, Muhammad Ali and AbraizKhattak, Mechanical, thermal, and electrical characterization of epoxy/silica composites for high-voltage insulation, Sci Eng Compos Mater, vol. 25, 2018, no. 4, 753-759.

15. Yun Chena B, DonghaiZhanga, XiaofengWua, HaoshengWanga, Chong Zhangb, Wei Yangb and Yunfa Chena, Epoxy/a-alumina nanocomposite with high electrical insulation performance, Prog Nat Sci-Mater., vol. 27, 2017, no. 5, pp. 574-581.

16. Krystian Leonard Chrzan, Jean M. Aandino, Ryszard Twarowski, Effects of acid rain on outdoor insulators, Inter. Conf. on Adv. in Proceed. testing and Appl. of Dielectr. Mater. 2001

17. K.I. Shrzanand H. Streubel, Artificial rain test of outdoor long rod insulators, Inter. Symp. on High Voltg Engg, Innes House, Johannesburg, 2009.

18. M.Suchitra, N.M. Renukappa, C. Ranganathaiah and J.Sundara Rajan Correlation of Free Space Length and Surface Energy of Nanocomposites to Surface Tracking, IEEE Trans. Dielectr. Electr. Insul., vol. 25, 2018, no. 6, pp. 2129-2138.

19. Ajith James Jose and M. Alagar, Development and Characterization of Organoclay-Filled Polyoxymethylene Nanocomposites for High Performance Applications, Polym. Compos., vol. 23, 2011, no. 9, pp. 1315-1324.

20. C. C. McDowell, B. D. Freeman and G. McNeely, Acetone sorption and uptake kinetic in poly (ethylene terephthalate), Polymer, vol. 4, 1999, pp. 3487-3499.

\section{AUTHORS PROFILE}

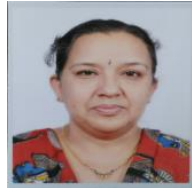

Santhy P. Kuruvilla, received M. Tech degree from Visvesvaraya Technological University, Belagavi, Karnataka, India in 2009 and the BE degree from Mahatma Gandhi University, Kerala in 1991. She is presently Assistant Professor in the department of Electronics and Communication at Maharaja Institute of technology, Mysuru, India. She is currently pursuing her Ph.D. at JSS Research Foundation, JSSTI campus, Mysuru, Karnataka, India.

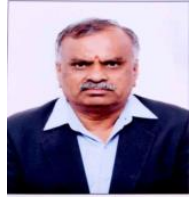

N M Renukappa received Ph.D degree from Visvesvaraya Technological University, Belagavi, Karnataka, India in 2007, M.S degree from Birla Institute of Technology and science, Pilani, India in 1996 and the BE degree from University of Mysore in 1992. He is presently Professor in the department of Electronics and Communication at JSS Science and Technology University, Mysuru, India. His research interest includes nano dielectrics and insulation system, power electronics, nanocomposites. 